\title{
Graphitic Cathodes for Aluminum Batteries with Aqueous Electrolytes
}

Jasmin Smajic $^{*[a]}$, Amira Alazmi ${ }^{[a],[b]}$, Nimer Wehbe ${ }^{[c]}$ and Pedro M. F. J. Costa*[a]

[a] Physical Science and Engineering Division, King Abdullah University of Science and Technology (KAUST), Thuwal 23955-6900, Saudi Arabia

[b] Department of Chemistry, University Colleges at Nairiyah, University of Hafr Al-Batin, Hafr Al-Batin 39524, Saudi Arabia

[c] Core Labs, King Abdullah University of Science and Technology (KAUST), Thuwal 23955-6900, Saudi Arabia

E-mail: jasmin.smajic@kaust.edu.sa; pedro.dacosta@kaust.edu.sa

\begin{abstract}
Concerns over lithium-ion battery safety and environmental impact have led to increased exploration of alternative energy storage systems. Of these, aluminum is of particular interest, being environmentally friendly, safe and easy to handle. In this work, we explore graphitic cathodes with an aqueous electrolyte (aluminum trifluoromethanesulfonate) and study their electrochemical performance. Finally, a reduced graphene cathode with tailored porosity results in an eco-friendly and inherently safe rechargeable battery with promising electrochemical performance.
\end{abstract}

KEYWORDS: Carbon, Graphene, Aluminum, Aqueous electrolyte, Battery 


\section{INTRODUCTION}

Lithium-ion batteries (LIBs) have developed into a reliable and high energy density solution for consumer electronics. ${ }^{1,2}$ However, with the advent of electric vehicles and stationary electrochemical storage, there are mounting concerns related to their operational safety, cost and sustainability. ${ }^{3,4}$ In fact, until recently, little consideration had been given to the environmental aspects of lithium extraction, which is known to cause freshwater shortages, chemical pollution and other adverse effects on ecosystems. ${ }^{5}$

To address the above issues, much attention is being directed to alternative energy storage chemistries such as those based on $\mathrm{Na}, \mathrm{K}, \mathrm{Mg}, \mathrm{Zn}$ and $\mathrm{Al}$ metals. ${ }^{6-10} \mathrm{Of}$ these, aluminum batteries are particularly interesting. $\mathrm{Al}$ is considered a "green metal" as it is environmentally friendly, safe and easy to handle. Besides, $\mathrm{Al}$ is the most abundant metal in the Earth's crust, with an industrially mature approach for mineral extraction, processing and recycling. In particular, its recycling is economically attractive because of the overall low energy consumption (an estimated 5\% of the energy needed to mine and process the ores). Today, $90 \%$ of $\mathrm{Al}$ used in transportation and construction and around $75 \%$ of all that was mined is still in circulation. ${ }^{11-14}$ Hence, aluminum is a prime resource to build a circular economy industry. Adding to this, and from an electrochemical perspective, Al can store three charge equivalents per mole, leading to theoretical gravimetric and volumetric capacities of $2980 \mathrm{mAh} \mathrm{g}^{-1}$ and $8046 \mathrm{mAh} \mathrm{cm}^{-3}$, respectively. These values are some of the highest known for battery materials. ${ }^{15,16}$

For decades, the promise of Al-batteries has been delayed by the lack of compatible electrolytes and cathodes. Aqueous electrolytes are the most desirable, due to safety and sustainability, but their adoption has largely failed as an oxide surface layer forms spontaneously on Al metal plates (anode) contacting water. In such circumstances, potentials that exceed the thermodynamic stability of water are required for the electrochemical cell to operate. Consequently, non-aqueous ionic liquids (IL) have been the electrolyte of choice. ${ }^{17-19}$ In the most popular option, employing a deep eutectic melt based on $\mathrm{AlCl}_{3}$ and IL generates a solid electrolyte interface (SEI) that enables reversible stripping and plating of $\mathrm{Al}$, mediated by the interconversion of $\mathrm{AlCl}_{4}^{-}$and $\mathrm{Al}_{2} \mathrm{Cl}_{7}{ }^{9,20-25}$ Regrettably, depending on their structural composition, these electrolytes can be toxic, or their biodegradability an issue. Additional challenges include their high cost, corrosivity and moisture sensitivity. ${ }^{26-31}$

The interest in aqueous electrolytes for Al-batteries was revived recently when Zhao et al. proposed an elegant step to make them compatible with $\mathrm{Al}$ anodes. ${ }^{32}$ By first dipping the $\mathrm{Al}$ plate in an $\mathrm{AlCl}_{3}-\mathrm{IL}$ mixture, a protective coating is obtained that acts as an "artificial SEI" and prevents direct contact between the Al metal and aqueous electrolyte. Most importantly, the amount of $\mathrm{AlCl}_{3}-\mathrm{IL}$ needed is minimal. At present, there are few reports where the ex-situ "artificial SEI" is employed. In those, the choice of the cathode 
active material is rather limited, mostly metal oxides. ${ }^{32-34}$ Despite showing promising capacity performance, the oxide-based cathodes suffer from inadequate stability and low capacity retention. Curiously, carbon cathodes, a popular choice in batteries, have not been explored for aqueous Al-batteries integrating the above-mentioned "artificial SEI". 35,36

Here, in a bid to fabricate a low-cost, stable and environmentally friendly Al-battery, we build on top of Zhao's conclusions and explore the stability of the "artificial SEI" approach in conjunction with a salt-water electrolyte and several graphitic carbon cathodes. ${ }^{29} \mathrm{We}$ find that the composition of the aluminum oxide surface layer (at the anode) is severely affected by the $\mathrm{AlCl}_{3}$ - $\mathrm{IL}$ pretreatment and the electrolyte's salt concentration. In addition, we observe that the graphitic carbon powders can have very interesting cathodic performance, provided their structure and chemistry are carefully tailored for this function.

\section{RESULTS \& DISCUSSIONS}

The electrochemical window of aqueous electrolytes is notoriously narrow due to the $\mathrm{H}_{2}$ evolution that takes place at higher potentials. This electrolyte degradation ought to be avoided if the longevity of the cell is to be maintained and catastrophic pressure buildup is to be averted. Assuming this, our first step was to test the electrolyte's potential window of electrochemical stability. Popular amongst the group of "artificial SEI" $\mathrm{Al}$ anodes, the $\mathrm{Al}(\mathrm{OTF})_{3}$ salt was selected. ${ }^{32-34}$ Circulating between $\mathrm{Al}$ (as-received state) and glassy carbon electrodes, the electrochemical response of the electrolyte was studied as a function of $\mathrm{Al}(\mathrm{OTF})_{3}$ concentration (Figure S1). Increasing the concentration of the aluminum salt effectively expanded the stability window of the electrolyte and suppressed the electrolysis of water. While a $1 \mathrm{M}$ solution offered a window of $<0.5 \mathrm{~V}$, for a $2 \mathrm{M}$, the electrolyte was stable in the $0.2 \mathrm{~V}-2.2 \mathrm{~V}$ range. The $3 \mathrm{M}$ solution was stable for $2 \mathrm{~V}$, whereas the more concentrated $5 \mathrm{M}$ expanded the upper interval limit past the $3 \mathrm{~V}$ mark. The observed trend is an expected consequence of the tight binding between $\mathrm{Al}^{3+}$ and its water solvation shell $\left(\Delta \mathrm{G}_{\text {hydration }}=-4525 \mathrm{~kJ} \mathrm{~mol}^{-1}\right){ }^{37}$ Increasing the concentration of the Al salt results in less free water molecules, thus stronger potentials are needed to induce the electrolyte decomposition. This makes the electrolyte more stable and, on a first view, the $5 \mathrm{M}$ solution our best option. ${ }^{38}$

Apart from the stability window, the concentration of the electrolyte must be chosen in accordance to its compatibility with other cell components. For this reason, a different story emerges when looking into the effects of repeated plating and stripping of the $\mathrm{Al}$ anode. In Figure 1a, it is quite perceptible that the $5 \mathrm{M}$ electrolyte leads to an unreliable performance, with drifting potentials and an increase in polarization (from $\sim 0.7 \mathrm{~V}$ at $20 \mathrm{~h}$, to $1.0 \mathrm{~V}$ at $180 \mathrm{~h}$ ), possibly due to increased viscosity and reduced ionic conductivity. ${ }^{39} \mathrm{By}$ contrast, the other electrolyte concentrations result in much more stable responses and smaller polarization 
values $(0.35 \mathrm{~V}$ for $3 \mathrm{M} ; 0.3 \mathrm{~V}$ for $2 \mathrm{M} ; 0.25 \mathrm{~V}$ for $1 \mathrm{M})$. Nevertheless, both the $1 \mathrm{M}$ and the $3 \mathrm{M}$ show sharp overshoot tails after a $6 \mathrm{~h}$ rest, instead of the desirable flat potentials. Such deviations are a fingerprint of inhibited charging/discharging processes. The $2 \mathrm{M}$ concentration, on the other hand, provides an extremely stable environment.
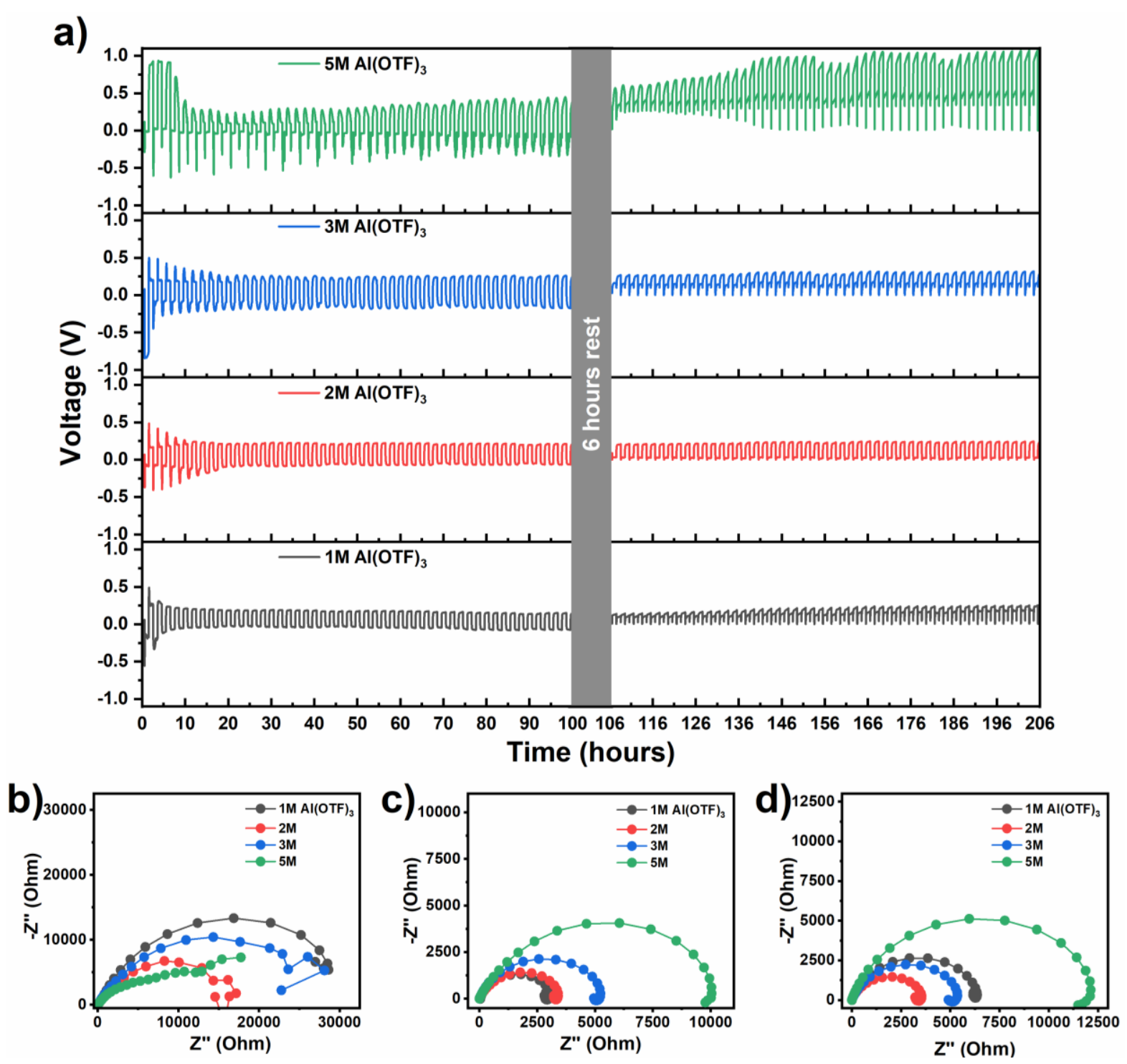

Figure 1. a) Long-term stability of the electrolyte under a cyclic load of $0.01 \mathrm{~mA} \mathrm{~cm}^{-2}$, b) EIS of the electrolyte before cycling, c) EIS of the electrolyte after $100 \mathrm{~h}$ of charge-discharge cycles and d) EIS of the electrolyte after $200 \mathrm{~h}$ of charge-discharge cycles.

To understand the interfacial resistances contributing to the polarization and their dependence on the salt's concentration, we probed the system at different time-points of the plating-stripping cycling $(0 \mathrm{~h}, 100 \mathrm{~h}$ and 200 h), using electrochemical impedance spectroscopy (EIS). Immediately after the assembly of the cells 
(at $0 \mathrm{~h}$ ), the EIS shows extremely high resistances. (Figure 1b). At this stage, the interface between the $\mathrm{Al}$ anode and the electrolyte is very immature and the inductive loops at low frequencies are indicative of its modification through ion adsorption processes. ${ }^{40,41}$ After $100 \mathrm{~h}$ of cycling (Figure 1c), lower resistances were seen. Both the $1 \mathrm{M}$ and $2 \mathrm{M}$ stand at around $3000 \Omega$, while the $3 \mathrm{M}$ and $5 \mathrm{M}$ show $5000 \Omega$ and $10000 \Omega$, respectively. By leaving the cells to rest for $6 \mathrm{~h}$ and cycling them for an additional $100 \mathrm{~h}$ (Figure 1d), a resistance of around $6500 \Omega$ is measured for the $1 \mathrm{M}$ electrolyte, while the $2 \mathrm{M}$ and $3 \mathrm{M}$ have resistances of $3000 \Omega$ and $5000 \Omega$, respectively. The $5 \mathrm{M}$ resistance increases to $12000 \Omega$. From this, it is clear that the interface between the Al plate and the electrolyte is heavily dependent on the salt's concentration and immersion time. If the concentration is too high or too low, the interface appears unstable as observed for the $1 \mathrm{M}$ and $5 \mathrm{M}$ electrolytes. On the other hand, both $2 \mathrm{M}$ and $3 \mathrm{M}$ appear stable and have low polarization values. In fact, the $2 \mathrm{M}$ has the lowest charge-transfer resistance and it is stable for more than $200 \mathrm{~h}$ of cycling (Figures 1a and 1d). Hereafter, in order to balance the interface stability, charge-transfer resistance and operational voltage window, a $2 \mathrm{M}$ electrolyte was used.

Even at the optimal salt's concentration, the charge-transfer resistance across the SEI on the Al plates remains too high for practical application. Hence, we looked into modifying the metal's surface by either polishing it with sandpaper (Emery, P1000), or exposing it to an $\mathrm{AlCl}_{3}$-IL electrolyte (to form an ex-situ "artificial SEI"). ${ }^{32}$ The analysis with EIS (Figure S2) shows that just polishing the foil reduces the resistance by one order of magnitude to $600 \Omega$ (cf. Figure $1 \mathbf{b}$ to $1 \mathrm{c}$ ). On the other hand, by just dipping the plate in the IL (as outlined by Zhao et al.), an even lower resistance of $250 \Omega$ is obtained. ${ }^{29}$ Clearly, mechanically removing the $\mathrm{Al}$ oxide film by polishing is not as good as the action of different organic and $\mathrm{Cl}$-containing species in the $\mathrm{AlCl}_{3}$-IL mixture, at least to obtain a stable and sufficiently conductive SEI. Thus, and in agreement with previous studies, we used $\mathrm{Al}$ anodes with the artificial SEI for the rest of the experiments.

Next, XPS was used to examine the chemical composition of the electrochemically cycled Al anode (after 100 cycles) that had the "artificial SEI" coating. A depth profile assessment was rendered possible by etching the Al plates with a high-energy Ar beam. Besides the survey XPS spectra (Figure S3), a highresolution analysis of the $\mathrm{Al} 2 \mathrm{p}, \mathrm{O} 1 \mathrm{~s}, \mathrm{C} 1 \mathrm{~s}$ and $\mathrm{S} 2 \mathrm{p}$ photoelectrons was performed before and after the etching procedure, with the plates in either charged or discharged states (Figure 2). All Al 2p spectra (Figure 2a) show two major features: 1) a smaller unsymmetrical signal, in the $72 \mathrm{eV}-70 \mathrm{eV}$ range, that is attributed to spin-orbit splitting in metallic aluminum, and 2) a dominant symmetrical peak, in the $77 \mathrm{eV}$ $-72 \mathrm{eV}$ range. The latter can arise from both the $\mathrm{Al}-\mathrm{Cl}$ component of the $\mathrm{SEI}$ and the $\mathrm{Al}-\mathrm{O} / \mathrm{Al}=\mathrm{O}$ bonds from the native oxide and solvated $\mathrm{Al}^{3+}$ ions. ${ }^{42,43}$ This explains the different binding energies (BE) of the peaks, before and after etching. For instance, with increased depth, the dominant peak $(77 \mathrm{eV}-72 \mathrm{eV}$ range) shifts to lower $\mathrm{BE}$ due to a decrease in $\mathrm{Al}-\mathrm{Cl}$ presence and a relative increase in contribution of Al- 
$\mathrm{O} / \mathrm{Al}=\mathrm{O}$ components. ${ }^{42}$ Similarly, the $\mathrm{BE}$ of the metallic aluminum $(72 \mathrm{eV}-70 \mathrm{eV})$ gets reduced postetching, explained by the differences between surface and bulk $\mathrm{Al}$ atoms. ${ }^{44}$ Curiously, the intensity of the metallic aluminum peaks, in charged state and before etching, resembles that in discharged state after etching. A possible explanation is the partial electrodeposition of Al on top of the ex-situ "artificial SEI" layer. This is opposite to the discharged state, wherein the metallic aluminum peak before etching has a significantly lower intensity than the post-etching one. We understand it as a consequence of the solvated $\mathrm{Al}$ ions migrating towards the anode during charging and diffusing in the opposite direction (i.e. away from the anode) during discharge. This is further confirmed by the higher BE of the charged state after etching.
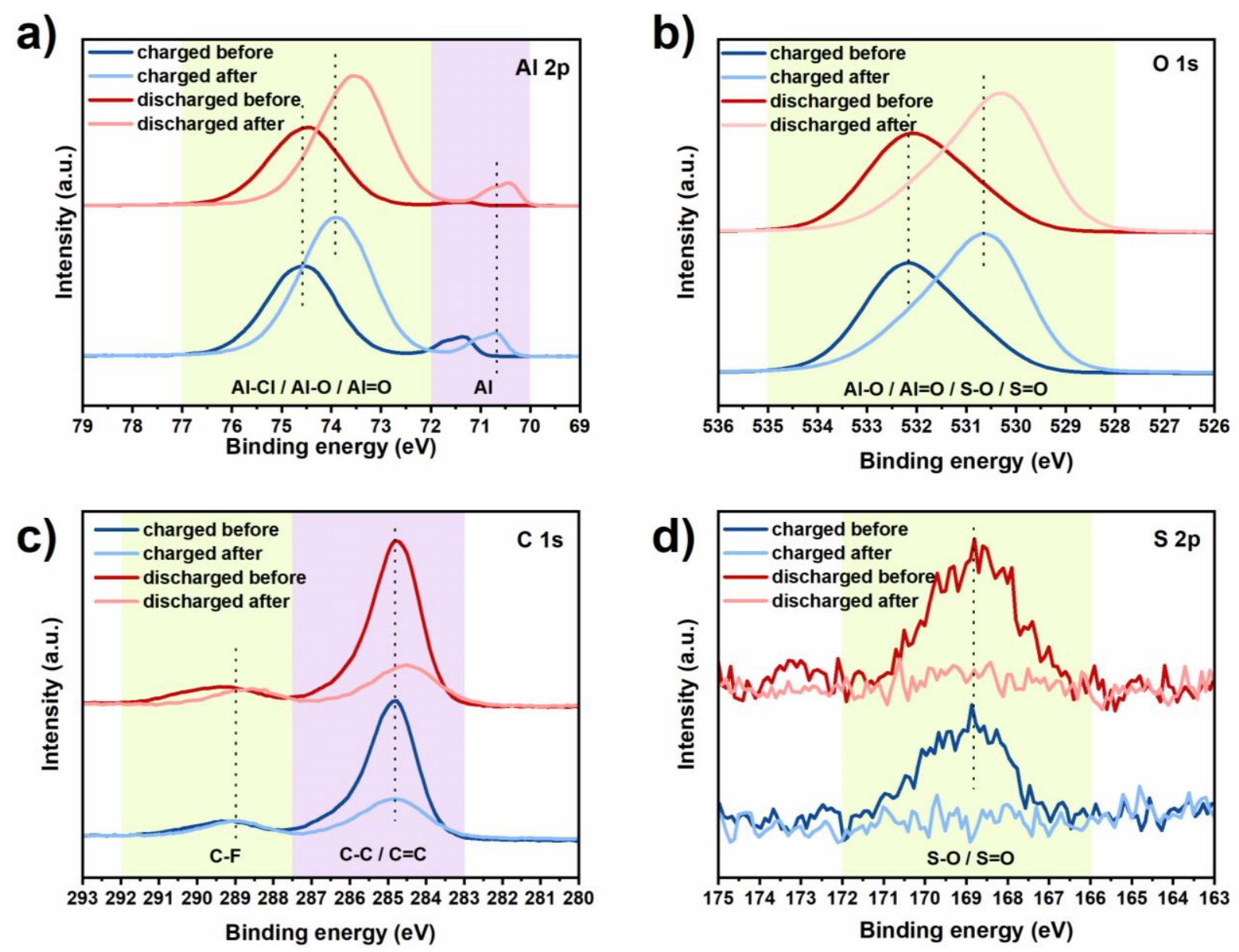

Figure 2. High-resolution XPS spectra of the $\mathrm{Al}$ anode, in charged and discharged states, before and after the etching step: a) Al 2p, b) O 1s, c) C 1s and d) S 2p. The dashed lines are guides for the eyes. The legends of chemical bonds refer to the regions (outlined in green and purple colored background) where they are commonly found.

The $\mathrm{Al} 2 \mathrm{p}$ analysis was complemented by the $\mathrm{O} 1 \mathrm{~s}$ study (Figure 2b). Again, a BE shift was observed as a function of depth. The peaks are asymmetric and can originate from the electrolyte $(\mathrm{S}-\mathrm{O} / \mathrm{S}=\mathrm{O}$ present in 
$\mathrm{CF}_{3} \mathrm{SO}_{3}{ }^{-}$), the $\mathrm{Al}^{3+}$ solvation shell (Al-O) and the native aluminum oxide ( $\left.\mathrm{Al}-\mathrm{O} / \mathrm{Al}=\mathrm{O}\right)$. The etching step resulted in a $\sim 2 \mathrm{eV}$ shift to lower BE. This is explained by the elimination of the IL component and subsequent exposure of the aluminum oxide, in agreement with the Al 2p findings. After etching, the visibly higher BE of the charged state is explained by an increased presence of solvated $\mathrm{Al}$ ions. Not surprisingly, the $\mathrm{C} 1 \mathrm{~s}$ and $\mathrm{S} 2 \mathrm{p}$ spectra are less informative (Figures $\mathbf{2 c}$ and $\mathbf{2 d}$, respectively). The $\mathrm{C} 1 \mathrm{~s}$ spectrum consists of two main peaks. The smaller one, in the $291 \mathrm{eV}-288 \mathrm{eV}$ range, is attributed to the C-F from the electrolyte and has constant intensity. The dominant peak, in the $287 \mathrm{eV}-283 \mathrm{eV}$ range, originates from the organic component of the ionic liquid, [EMIm] (i.e. $\mathrm{C}-\mathrm{C} / \mathrm{C}=\mathrm{C}$ ), that integrates the $\mathrm{AlCl}_{3}-\mathrm{IL}$ pretreatment. ${ }^{45}$ This is also the region of adventitious $\mathrm{C}(284.8 \mathrm{eV})$. Upon etching, its intensity decreases significantly, as expected. Likewise, the $\mathrm{S} 2 \mathrm{p}$ peaks (from the $\mathrm{SO}_{3}{ }^{-}$of the $\mathrm{Al}(\mathrm{OTF}$ ) electrolyte) vanish after etching. Following the peak shift analysis, the elements identified with XPS were quantified, before and after etching (Table 1).

Table 1. Elemental analysis (at\%) of the $\mathrm{Al}$ anode's surface, as calculated from XPS measurements.

\begin{tabular}{lcccccc}
\hline & Al & O & C & S & F & Cl \\
\hline Charged before & 25.2 & 45.8 & 25.0 & 0.4 & 1.6 & 1.9 \\
Charged after & 34.3 & 52.8 & 11.4 & n/a & 0.8 & 0.6 \\
Discharged before & 21.7 & 45.5 & 29.7 & 0.4 & 1.3 & 0.3 \\
Discharged after & 33.7 & 52.4 & 11.4 & n/a & 0.6 & n/a \\
\hline
\end{tabular}

On average, the $\mathrm{Al}$ and $\mathrm{O}$ presence increases by $\sim 10$ at $\%$, while that of $\mathrm{C}$ decreases by $\sim 15$ at $\%$. Albeit present in small quantities before etching, the concentration of $\mathrm{F}$ and $\mathrm{Cl}$ decays further, indicating limited but stable adsorption on the anode. On the other hand, the little $S$ that was identified, decreases below the detection limit after etching. Taken together, the native aluminum oxide layer in the anode is clearly affected by the IL pretreatment. However, the IL coating is also modified by the electrolyte. An SEM analysis of the surface (Figure S4) identified pits, indicating that the aforementioned SEI does not inhibit the stripping of $\mathrm{Al}^{3+}$ ions.

After identifying the characteristics of the cycled Al anode, we questioned the available repertoire of cathodes for aqueous Al batteries. Confronted with the predominance of metal oxides, we looked for possible alternatives and tested two of the most common carbon electrode materials: graphite and expanded graphite (i.e. processed expanded graphite, see Experimental Section). As seen in Figure 3a, their cyclic voltammetry exhibit broad redox peaks that can be attributed to the intercalation of ions into the layered carbons. 
a)

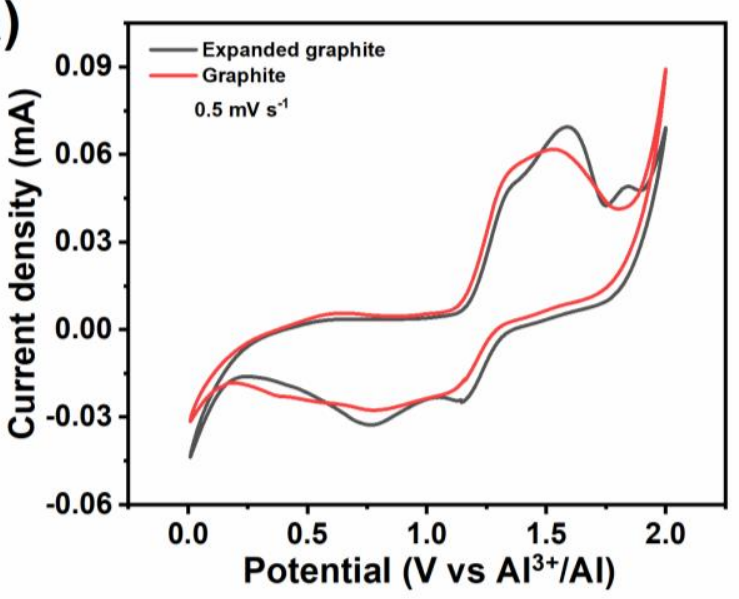

b)

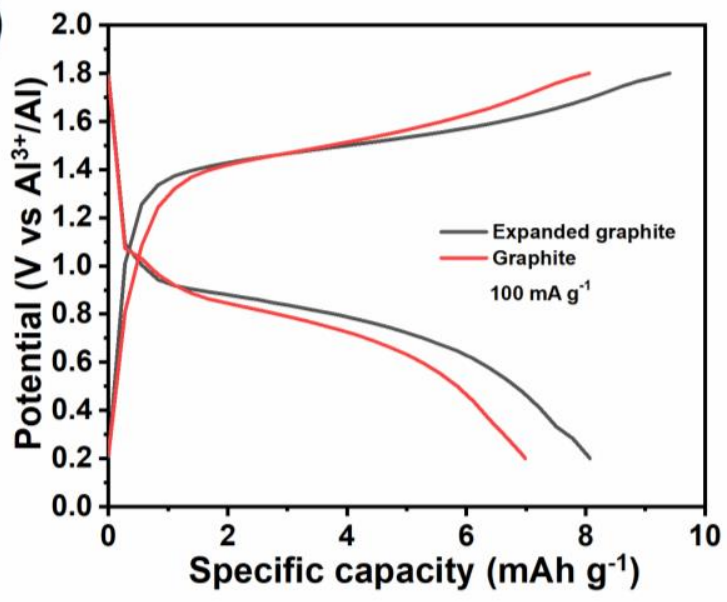

c)

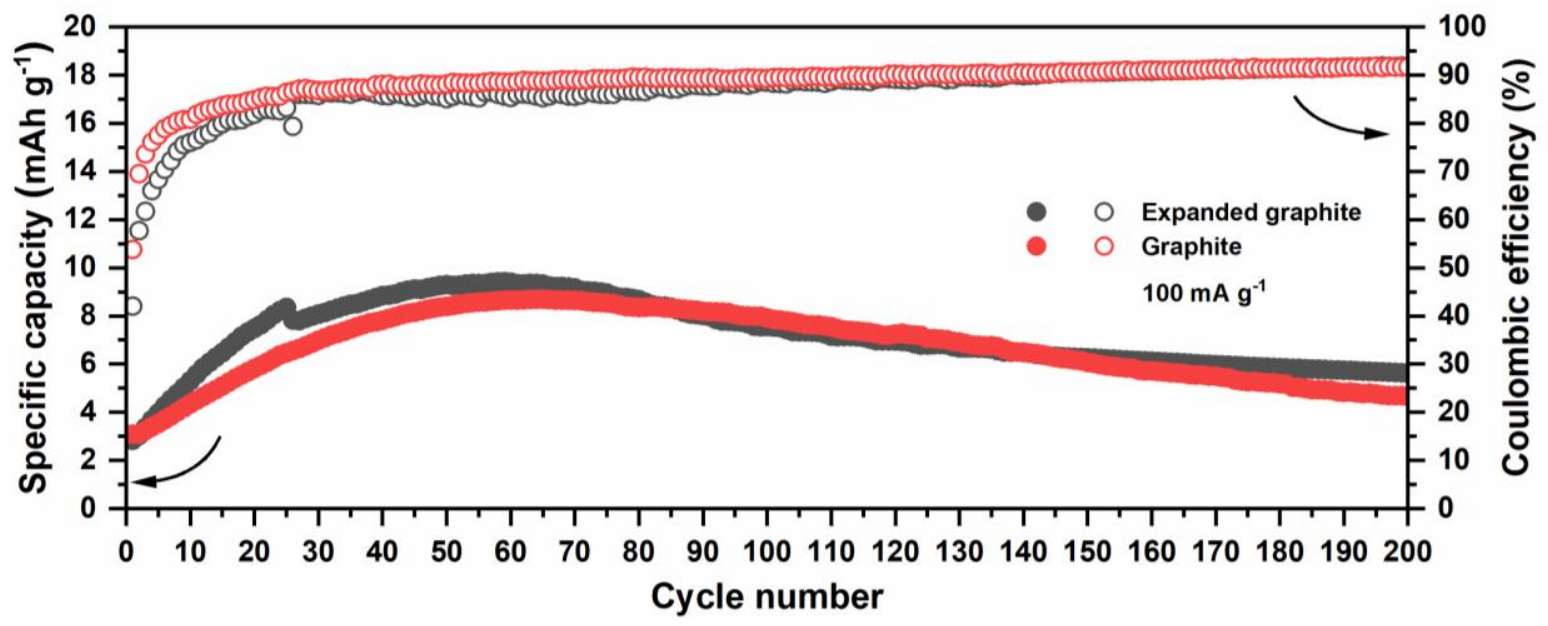

Figure 3. Electrochemical performance of the graphite and expanded graphite cathode: a) cyclic voltammetry, b) voltage profiles and c) cycling stability.

The voltage curves (Figure 3b) show plateaus centered at $0.9 \mathrm{~V}$ and $1.4 \mathrm{~V}$, for discharge and charge, respectively. These agree well with the cyclic voltammetry. The capacity, however, peaks at around 10 $\mathrm{mAh} \mathrm{g}^{-1}$ (Figure 3c), declining by $\sim 50 \%$ after 200 cycles. Assuming that the $\mathrm{Al}^{3+}$ (a strong Lewis acid) remains solvated throughout, this behavior is a likely consequence of the large size of the intercalant $(0.38$ $\mathrm{nm}){ }^{46}$ This hypothesis is also supported by a slightly higher capacity of expanded graphite, due to its expanded interlayer distance. Carbons are a versatile family of materials. Besides a number of allotropes, it is possible to tailor their structure and surface chemistry. ${ }^{47,48}$ In fact, depending on the process selected, powders derived from graphite can be modified to accommodate large ions. Previously, we demonstrated the importance of the drying method as we tuned the porosity of reduced graphene oxide (rGO) to optimize its performance for batteries and supercapacitors. ${ }^{20,49}$ Supercritical drying methods yield rGO powders with a moderate surface area and an average pore size of $20 \mathrm{~nm}$ that could accommodate the large size of solvated 
$\mathrm{Al}^{3+}$ ions through mostly pseudocapacitive charge storage. ${ }^{20,49}$ In these circumstances, allying the chemical stability of graphitic carbon powders to the mesoporosity of the rGOs could be advantageous when exploring alternative cathode materials for aqueous Al-batteries (Figure 4).
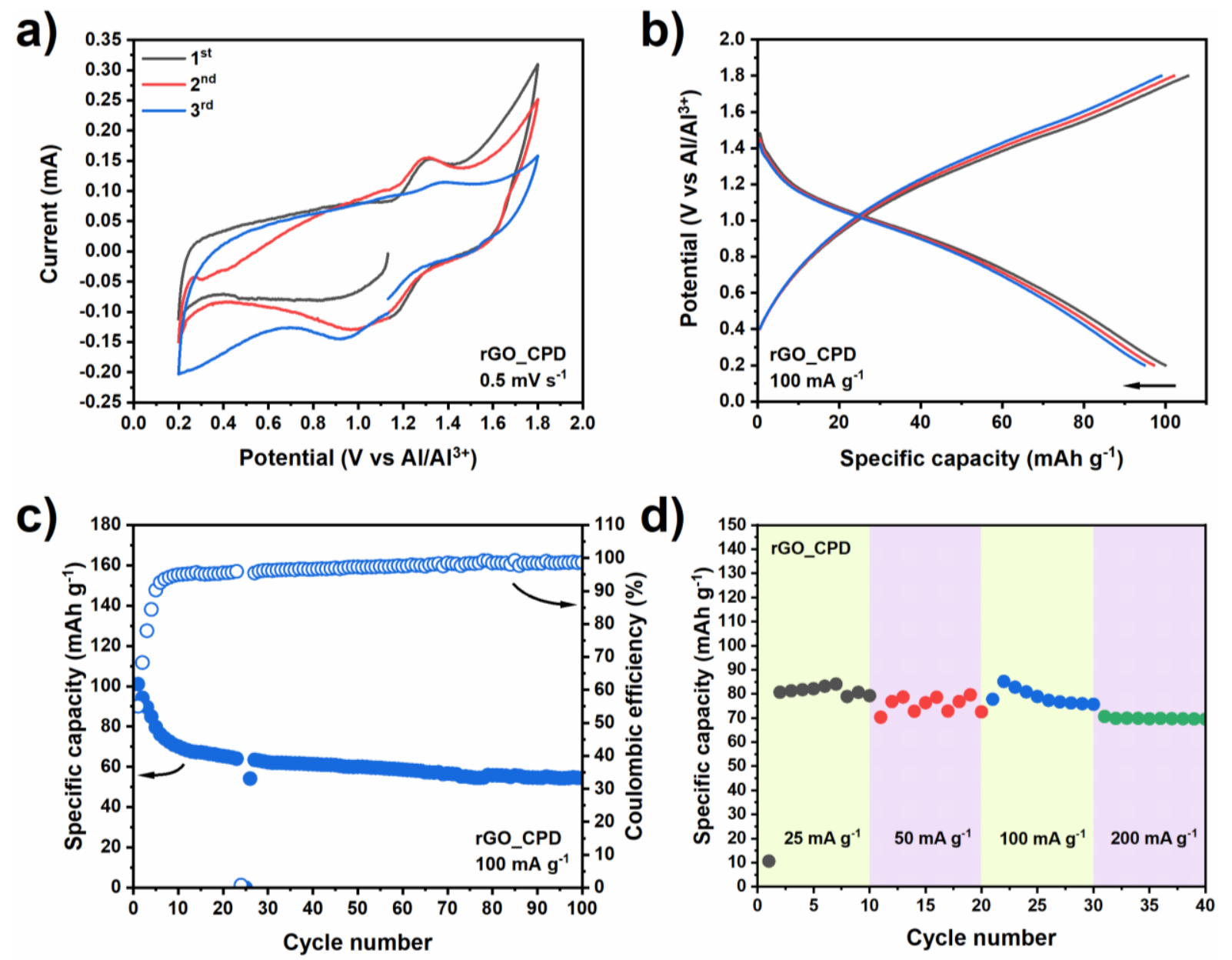

Figure 4. Electrochemical performance of the rGO_CPD: a) cyclic voltammetry, b) charge-discharge voltage profiles, c) cycling stability with Coulombic efficiency and d) rate capability.

As seen in Figure 4, the supercritically-dried rGO (rGO_CPD) exhibits vastly superior performance than both graphite and expanded graphite. Its cyclic voltammogram (Figure 4a) shows broad at peaks $1.0 \mathrm{~V}$ and $1.3 \mathrm{~V}$ for discharge and charge, respectively. These values are similar to those previously found for graphite and expanded graphite, however, their intensity is lower and the area enclosed by the cyclic voltammogram curves is higher, indicating an increased pseudocapacitive component of the charge-storage mechanism. The voltage curves (Figure $4 \mathbf{b}$ ) show sloping profiles, instead of plateaus, in agreement with the pseudocapacitive character of the electrode and justifies the remarkable increase in capacity (by one order of magnitude), with the initial capacity at $\sim 100 \mathrm{mAh} \mathrm{g}^{-1}$. Furthermore, the rGO_CPD's cycling stability and 
the Coulombic efficiency are also superior (Figure 4c), with $77 \%$ of capacity retention between $10^{\text {th }}$ and $100^{\text {th }}$ cycle at a constant Coulombic efficiency of $\sim 98 \%$. Finally, its rate capability (Figure 4d) yields similar capacities for different current densities, confirming the resilience of the rGO_CPD cathode. Such a response speaks to the stability and efficiency of this system. It also demonstrates that "opening up" the graphitic structure (by increasing the surface area and inducing mesoporosity), successfully overcomes the inherent limitations of the large ion size. Ultimately, the $\sim 20 \mathrm{~nm}$ mesopores network of the rGO_CPD enables a better wetting of the cathode mass as well as facilitating the access of the $\mathrm{Al}$ ions to redox-active sites..$^{50}$

\section{CONCLUSIONS}

A modified $\mathrm{Al}$ anode, a reduced graphene oxide cathode and a $2 \mathrm{M} \mathrm{Al}(\mathrm{OTF})_{3}$ electrolyte can be used to form an eco-friendly and inherently safe rechargeable battery. We find that the SEI layer on the Al anode is dependent on both the pretreatment method and the electrolyte. Further to this, increasing the pseudocapacitive component of the carbon cathode is beneficial in improving the electrochemical performance of an aqueous Al-battery.

\section{EXPERIMENTAL}

\section{Materials Synthesis}

Graphite (Alfa Aesar; 99.99\% purity; $44 \mu \mathrm{m}$ average flake size) and expanded graphite were used asreceived. ${ }^{51}$ To prepare the reduced graphene oxide (rGO), we followed a procedure described elsewhere. ${ }^{50}$ Briefly, graphite powder (99\%, crystalline, 325 mesh, Alfa Aesar) was oxidized and exfoliated using the improved Hummers' method. Following this, the graphene oxide (GO) powder was dried with supercritical $\mathrm{CO}_{2}$ for $24 \mathrm{~h}$, and hydrothermally reduced, at $180^{\circ} \mathrm{C}$ for $24 \mathrm{~h}$. Upon collection, the rGO product was dried under supercritical conditions (for $24 \mathrm{~h}$ ).

The aqueous electrolyte was prepared by mixing the salt aluminum trifluoromethanesulfonate $\mathrm{Al}(\mathrm{OTF})_{3}$ (Alfa Aesar) with appropriate volumes of deionized water to obtain various concentrations, 1M, 2M, 3M and 5M. To prepare the ionic liquid electrolyte, 1-ethyl-3-methyl imidazolium chloride [EMIm]Cl was first annealed in a tube furnace, in vacuo, at $70{ }^{\circ} \mathrm{C}$ and for $16 \mathrm{~h}$, to remove residual water. This powder was then introduced into an Ar-filled glove box (MBraun LabStar, $<0.5 \mathrm{ppm} \mathrm{O}_{2},<0.5 \mathrm{ppm} \mathrm{H}_{2} \mathrm{O}$ ), always avoiding exposure to air. The anhydrous $\mathrm{AlCl}_{3}$ powder was used as received from the vendor (Alfa Aesar). With these two components, the $\mathrm{AlCl}_{3}:[\mathrm{EMIm}] \mathrm{Cl}=1.3\left(\mathrm{~mol} \mathrm{~mol}^{-1}\right)$ electrolyte was prepared by slowly adding 
the $\mathrm{AlCl}_{3}$ to $[\mathrm{EMIm}] \mathrm{Cl}$, inside the glove box. Mixing of the two powders produced a clear light-yellow liquid through an exothermic reaction. Finally, the obtained electrolyte was stirred for $30 \mathrm{~min}$ and left to stand.

\section{Materials Characterization}

Optical microscopy was performed on a Zeiss STEMI 2000-C. The X-ray photoelectron spectroscopy (XPS) characterization was done on a Kratos Axis Ultra, equipped with a monochromatic Al K $\alpha$ X-ray source $(\mathrm{h} v=1486.6 \mathrm{eV})$ and operated at a power of $150 \mathrm{~W}$ under ultrahigh-vacuum conditions $\left(10^{-9} \mathrm{mbar}\right)$. The etching process was performed using argon cluster beam Ar500+, operated at $5 \mathrm{keV}$. The raster size of the etched area was about $4 \mathrm{~mm} \times 4 \mathrm{~mm}$ and the etching was done until $\mathrm{S}$ could not be detected $(\sim 30-50$ $\mathrm{nm})$. The spectra were collected from the middle of the etched area, in order to avoid the edge effect.

\section{Electrochemical Measurements}

The electrochemical studies were made with two potentiostats, a Bio-Logic VMP3 and a BCS-800, in a 2023 coin cell configuration. Electrochemical impedance spectroscopy (EIS) was carried out from $10 \mathrm{mHz}$ to $100 \mathrm{kHz}$ with an amplitude of $10 \mathrm{mV}$. The cells were assembled using the carbon powders and an $\mathrm{Al}$ foil (99.999\%, $0.25 \mathrm{~mm}$, Sigma-Aldrich) as the active electrode materials (cathode and anode, respectively). The cathode was prepared by sandwiching the carbons $\left(\sim 1 \mathrm{mg} \mathrm{cm}^{-2}\right)$ between a glass fiber separator and a current collector. No binders were used. Carbon paper was the current collector of choice for the electrochemical performance assessment. In all experiments, $100 \mu 1$ of aqueous electrolyte was used for each cell.

\section{Data availability}

The raw/processed data required to reproduce these findings cannot be shared at this time as the data also forms part of an ongoing study.

\section{Acknowledgements}

This work was funded by KAUST (BAS/1/1346-01-01). The authors thank the KAUST Core Labs for technical assistance.

\section{Conflict of Interest}

Parts of this work have been filed as a provisional patent application (USPTO 63/186,362, filed: May 10, 2021). 


\section{REFERENCES}

1 Li, M., Lu, J., Chen, Z. \& Amine, K. 30 years of lithium-ion batteries. Advanced Materials 30, 1800561 (2018).

2 Smajic, J., Alazmi, A., Patole, S. P. \& Costa, Pedro M. F. J. Single-walled carbon nanotubes as stabilizing agents in red phosphorus Li-ion battery anodes. RSC Advances 7, 39997-40004 (2017).

3 Scrosati, B. \& Garche, J. Lithium batteries: Status, prospects and future. Journal of Power Sources 195, 2419-2430 (2010).

4 Choi, J. W. \& Aurbach, D. Promise and reality of post-lithium-ion batteries with high energy densities. Nature Reviews Materials 1, 1-16 (2016).

5 Wanger, T. C. The Lithium future-resources, recycling, and the environment. Conservation Letters 4, 202-206 (2011).

6 Hwang, J. Y., Myung, S. T. \& Sun, Y. K. Recent progress in rechargeable potassium batteries. Advanced Functional Materials 28, 1802938 (2018).

7 Mao, M., Gao, T., Hou, S. \& Wang, C. A critical review of cathodes for rechargeable Mg batteries. Chemical Society Reviews 47, 8804-8841 (2018).

8 Li, H., Ma, L., Han, C., Wang, Z., Liu, Z., Tang, Z. \& Zhi, C. Advanced rechargeable zinc-based batteries: Recent progress and future perspectives. Nano Energy 62, 550-587 (2019).

9 Lin, M.-C., Gong, M., Lu, B., Wu, Y., Wang, D.-Y., Guan, M., Angell, M., Chen, C., Yang, J. \& Hwang, B.-J. An ultrafast rechargeable aluminium-ion battery. Nature 520, 324-328 (2015).

10 Vaalma, C., Buchholz, D., Weil, M. \& Passerini, S. A cost and resource analysis of sodium-ion batteries. Nature Reviews Materials 3, 1-11 (2018).

11 Rombach, G. Raw material supply by aluminium recycling-Efficiency evaluation and long-term availability. Acta Materialia 61, 1012-1020 (2013).

12 Bertram, M., Hryniuk, M., Kirchner, G. \& Pruvost, F. Aluminium recycling in Europe: the road to high quality products. (European Aluminum Association, 2006).

13 Bertram, M., Martchek, K. J. \& Rombach, G. Material flow analysis in the aluminum industry. Journal of Industrial Ecology 13, 650-654 (2009).

14 Bai, Y., Essehli, R., Jafta, C. J., Livingston, K. M. \& Belharouak, I. Recovery of cathode materials and aluminum foil using a green solvent. ACS Sustainable Chemistry \& Engineering $\mathbf{9}$, 6048-6055 (2021).

15 Lide, D. R. CRC Handbook of Chemistry and Physics. Vol. 85 (CRC press, 2004).

16 Zhang, M., Xiang, L., Galluzzi, M., Jiang, C., Zhang, S., Li, J. \& Tang, Y. Uniform distribution of alloying/dealloying stress for high structural stability of an $\mathrm{Al}$ anode in high-areal-density lithium-ion batteries. Advanced Materials 31, 1900826 (2019).

17 Zhou, J., Yu, X., Zhou, J. \& Lu, B. Polyimide/metal-organic framework hybrid for high performance Al-Organic battery. Energy Storage Materials 31, 58-63 (2020).

18 Lin, M. C., Gong, M., Lu, B., Wu, Y., Wang, D. Y., Guan, M., Angell, M., Chen, C., Yang, J., Hwang, B. J. \& Dai, H. An ultrafast rechargeable aluminium-ion battery. Nature 520, 325-328 (2015).

19 Faegh, E., Ng, B., Hayman, D. \& Mustain, W. E. Practical assessment of the performance of aluminium battery technologies. Nature Energy 6, 21-29 (2021).

20 Smajic, J., Alazmi, A., Batra, N., Palanisamy, T., Anjum, D. H. \& Costa, P. M. Mesoporous reduced graphene oxide as a high capacity cathode for aluminum batteries. Small 14, 1803584 (2018).

21 Smajic, J., Wee, S., Simoes, F. R. F., Hedhili, M. N., Wehbe, N., Abou-Hamad, E. \& Costa, P. M. Capacity retention analysis in aluminum-sulfur batteries. ACS Applied Energy Materials 3, 68056814 (2020). 
22 Wu, Y., Gong, M., Lin, M.-C., Yuan, C., Angell, M., Huang, L., Wang, D.-Y., Zhang, X., Yang, J., Hwang, B.-J. \& Dai, H. 3D graphitic foams derived from chloroaluminate anion intercalation for ultrafast aluminum-ion battery. Advanced Materials 28, 9218-9222 (2016).

23 Wang, S., Yu, Z., Tu, J., Wang, J., Tian, D., Liu, Y. \& Jiao, S. A novel aluminum-ion battery: $\mathrm{Al} / \mathrm{AlCl}_{3}-[\mathrm{EMIm}] \mathrm{Cl} / \mathrm{Ni}_{3} \mathrm{~S}_{2} @$ graphene. Advanced Energy Materials 6, 1600137 (2016).

$24 \mathrm{Hu}$, Y., Luo, B., Ye, D., Zhu, X., Lyu, M. \& Wang, L. An innovative freeze-dried reduced graphene oxide supported $\mathrm{SnS}_{2}$ cathode active material for aluminum-ion batteries. Advanced Materials 29, 1606132 (2017).

25 Zhang, L., Chen, L., Luo, H., Zhou, X. \& Liu, Z. Large-sized few-layer graphene enables an ultrafast and long-life aluminum-ion battery. Advanced Energy Materials 7, 1700034 (2017).

26 Leitch, A. C., Abdelghany, T. M., Probert, P. M., Dunn, M. P., Meyer, S. K., Palmer, J. M., Cooke, M. P., Blake, L. I., Morse, K. \& Rosenmai, A. K. The toxicity of the methylimidazolium ionic liquids, with a focus on M8OI and hepatic effects. Food and Chemical Toxicology 136, 111069 (2020).

27 Bubalo, M. C., Radošević, K., Redovniković, I. R., Slivac, I. \& Srček, V. G. Toxicity mechanisms of ionic liquids. Archives of Industrial Hygiene and Toxicology 68, 171-179 (2017).

28 Smajic, J., Simoes, F. R. F. \& Costa, P. M. F. J. How metallic impurities in carbon cathodes affect the electrochemistry of aluminum batteries. ChemElectroChem 7, 4810-4814 (2020). Smajic, J., Alazmi, A. \& Costa, P. M. F. J. The Role of the binder/solvent pair on the electrochemical performance of aluminium batteries. MRS Advances 4, 807-812 (2019).

30 Shi, J., Zhang, J. \& Guo, J. Avoiding pitfalls in rechargeable aluminum batteries research. ACS Energy Letters 4, 2124-2129 (2019).

31 Costa, S. P., Azevedo, A. M., Pinto, P. C. \& Saraiva, M. L. M. Environmental impact of ionic liquids: recent advances in (eco) toxicology and (bio) degradability. ChemSusChem 10, 23212347 (2017).

32 Zhao, Q., Zachman, M. J., Al Sadat, W. I., Zheng, J., Kourkoutis, L. F. \& Archer, L. Solid electrolyte interphases for high-energy aqueous aluminum electrochemical cells. Science Advances 4, eaau8131 (2018).

33 Zhao, Q., Liu, L., Yin, J., Zheng, J., Zhang, D., Chen, J. \& Archer, L. Proton intercalation/deintercalation dynamics in vanadium oxides for aqueous aluminum electrochemical cells. Angewandte Chemie 59, 3048-3052 (2019).

34 Cai, Y., Kumar, S., Chua, R., Verma, V., Du, Y., Kou, Z., Ren, H., Arora, H. \& Srinivasan, M. Bronze-type vanadium dioxide holey nanobelts as high performing cathode material for aqueous aluminium-ion battery. Journal of Materials Chemistry A 8, 12716-12722 (2020).

35 Nandi, S. \& Das, S. K. Realizing a low-cost and sustainable rechargeable aqueous aluminummetal battery with exfoliated graphite cathode. ACS Sustainable Chemistry \& Engineering (2019).

36 Zhang, Q., Cheng, X., Wang, C., Rao, A. M. \& Lu, B. Sulfur-assisted large-scale synthesis of graphene microspheres for superior potassium-ion batteries. Energy \& Environmental Science 14, 965-974 (2021).

37 Marcus, Y. Thermodynamics of solvation of ions. Part 5.- Gibbs free energy of hydration at 298.15 K. Journal of the Chemical Society, Faraday Transactions 87, 2995-2999 (1991).

38 Suo, L., Borodin, O., Gao, T., Olguin, M., Ho, J., Fan, X., Luo, C., Wang, C. \& Xu, K. "Waterin-salt" electrolyte enables high-voltage aqueous lithium-ion chemistries. Science 350, 938-943 (2015).

39 Kumar, S., Verma, V., Arora, H., Manalastas Jr, W. \& Srinivasan, M. Rechargeable Al-metal aqueous battery using $\mathrm{NaMnHCF}$ as a cathode: investigating the role of coated-Al anode treatments for superior battery cycling performance. ACS Applied Energy Materials 3, 8627-8635 (2020). 
40 Xu, L.-n., Zhu, J.-y., Lu, M.-x., Zhang, L. \& Chang, W. Electrochemical impedance spectroscopy study on the corrosion of the weld zone of $3 \mathrm{Cr}$ steel welded joints in $\mathrm{CO} 2$ environments. International Journal of Minerals, Metallurgy, and Materials 22, 500-508 (2015).

41 Boukamp, B. A. Interpretation of an 'inductive loop' in the impedance of an oxygen ion conducting electrolyte/metal electrode system. Solid State Ionics 143, 47-55 (2001).

42 Sherwood, P. M. Introduction to studies of aluminum and its compounds by XPS. Surface Science Spectra 5, 1-3 (1998).

43 Elmi, C., Guggenheim, S. \& Gieré, R. Surface crystal chemistry of phyllosilicates using X-ray photoelectron spectroscopy: A review. Clays and Clay Minerals 64, 537-551 (2016).

44 Bagus, P., Pacchioni, G. \& Parmigiani, F. Surface core-level spectroscopy of $\mathrm{Cu}(100)$ and Al (100). Physical Review B 43, 5172 (1991).

45 Palchan, I., Crespin, M., Estrade-Szwarckopf, H. \& Rousseau, B. Graphite fluorides: an XPS study of a new type of CF bonding. Chemical Physics Letters 157, 321-327 (1989).

46 Marcus, Y. Ionic radii in aqueous solutions. Chemical Reviews 88, 1475-1498 (1988).

47 Batra, N. M., Ashokkumar, A. E., Smajic, J., Enyashin, A. N., Deepak, F. L. \& Costa, P. M. Morphological phase diagram of gadolinium iodide encapsulated in carbon nanotubes. The Journal of Physical Chemistry C 122, 24967-24976 (2018).

48 Wang, Y., Zhang, M., Shen, X., Wang, H., Wang, H., Xia, K., Yin, Z. \& Zhang, Y. Biomassderived carbon materials: controllable preparation and versatile applications. Small, 2008079 (2021).

49 Alazmi, A., El Tall, O., Rasul, S., Hedhili, M. N., Patole, S. P. \& Costa, P. M. A process to enhance the specific surface area and capacitance of hydrothermally reduced graphene oxide. Nanoscale 8, 17782-17787 (2016).

50 Alazmi, A., Rasul, S., Patole, S. P. \& Costa, P. M. Comparative study of synthesis and reduction methods for graphene oxide. Polyhedron 116, 153-161 (2016).

51 Alzahrani, A. A. Production of High-quality Few-layer Graphene Flakes by Intercalation and Exfoliation (2017). 